\title{
Organic Melt Crystallization as a Method for Synthesis of Supramolecular Complexes
}

\author{
Masaaki Yokota*, Ryota Nakamura, Norihito Doki \\ Department of Chemistry and Bioengineering, Iwate University, Morioka, Japan \\ Email: "myokota@iwate-u.ac.jp
}

Received 18 December 2015; accepted 5 April 2016; published 8 April 2016

Copyright $(\underset{2016}{ } 2 \mathrm{by}$ authors and Scientific Research Publishing Inc.

This work is licensed under the Creative Commons Attribution International License (CC BY). http://creativecommons.org/licenses/by/4.0/

c) (i) Open Access

\begin{abstract}
The most simple method for solventless synthesis of supramolecular complex of CMCR·2BPY·BZP, $[C M C R=C$-methylcalix [4] resorcinarene, $B P Y=4,4$ '-bipyridine, $B Z P=$ benzophenone $]$, is proposed. Although CMCR by itself is high melting point compound (above $300^{\circ} \mathrm{C}$ ), CMCR was found to be dissolved in melt mixture of BPY and BZPeven below $120^{\circ} \mathrm{C}$. In the mixture of the three components, the reaction occurs to form CMCR·2BPY·BZP supramolecular complex.
\end{abstract}

\section{Keywords}

Crystallization, Supramolecular Complex, Solventless Synthesis, Melting Point

\section{Introduction}

Organic synthesis creates a molecule of interest by adding atomic group. While, the supramolecular synthesis is a self-assembly of several types of molecular species as the building block. In the latter case, intermolecular interaction is important. Control of the intermolecular interaction is considered difficult and many efforts have been paid for the problem. There are also other interests, structure-property relation, for supramolecular complex. Once a supramolecular complex with a required property is found, variety of complexes with the similar structure may be developed easily, just by changing the ligands and/or guests. This leads to a tuning of properties. Thus, one may say that supramolecular complexes have the infinity of possibilities.

Usually, supramolecular complexes have been synthesized by homogeneous solution method such as hydrothermal methods. Since the reaction rate is slow, the hydrothermal method requires a long time to form the products. To avoid the demerit of the hydrothermal methods, mechanochemical methods have been applied for supramolecular synthesis [1]. In the mechanochemical methods, multi components of reaction compounds are ground in solid forms. The merit of the methods is solvent-free. Against this method, we have suggested essen-

${ }^{*}$ Corresponding author.

How to cite this paper: Yokota, M., Nakamura, R. and Doki, N. (2016) Organic Melt Crystallization as a Method for Synthesis of Supramolecular Complexes. Advances in Chemical Engineering and Science, 6, 76-81.

http://dx.doi.org/10.4236/aces.2016.62009 
tial point of the mechanochemical method is not mechanical shock but a generation of heat caused by grinding. Grinding of solid materials gives a heat by friction. Thus, the partially melting of the solids must occur and the reaction may begin at the melted interface. If it is true, one may hope occurrence of the reaction in more simple way. In our previous study, two organic reactants with lower melting points are in contact with each other and the two reactants were found to melt even at mild conditions to give a required reaction product [2]. However, there exist many reaction systems in which reaction species with high melting point is involved. Is it possible to apply our proposed melting method for such reaction systems? In this paper, the simple method that leads to an answer for this question is proposed.

\section{Experimental}

The supramolecular complex which is to be synthesized in this study is CMCR·2BPY $\cdot \mathrm{BZP}$ [CMCR $=C$-methylcalix[4]resorcinarene, BPY $=4,4^{\prime}$-bipyridine, BZP = benzophenone]. In literature, the supramolecule was synthesized by hydrothermal technique [3] and crystal structure of the molecule was also reported as shown in Figure 1. A host framework composed of CMCR as node and BPY as ligand is developed. Within the cavity of the host framework, the guest molecule of BZP (shown by space-fill model) is included. The position of the BZP is not fixed (disordered).

\subsection{Materials}

The chemical structures of reactants and reaction path are shown in Figure 2. All three materials used for synthesis of the supramolecular complex were purchased from commercially: C-Methylcalix[4]resorcinarene (CMCR, Sigma-Aldrich, purity > 90.0\%), 4,4'-Bipyridine (BPY, Tokyo Chemical Industry, purity > 98.0\%), Benzophenone (BZP, purity $>99.0 \%$, Tokyo Chemical Industry). Measured melting point of these compounds are as follows: $\mathrm{BZP}=48^{\circ} \mathrm{C}, \mathrm{BPY}=111^{\circ} \mathrm{C}$, CMCR $>300^{\circ} \mathrm{C}$ (unmeasurable caused by decomposition and/or sublimation above $300^{\circ} \mathrm{C}$ ). The values of the melting points are important in this manuscript.

\subsection{Method}

Before the synthesis of the supramolecular complex, the three reactant substances, CMCR, BPY, BZP, were ground separately using a mortar and pestle in order for the increase of reaction surface in the next step of the experiment. The ground reactants were weighed (CMCR:BPY:BZP = 1:2:1 in molar ratio) and mixed gently to avoid reaction caused by friction. Then the physical mixtures of the powder was set on a heating device and the

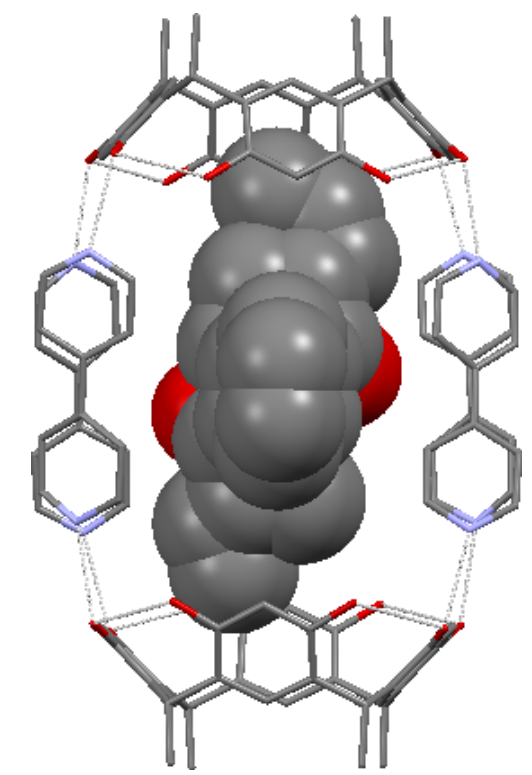

Figure 1. Crystal structure of CMCR·2BPY·BZP supramolecular complex drawn using literature data [3]. 
<smiles>CC(c1cccc(-c2cc[n+]([I-])cc2)c1)c1cc(C(C)c2cc(C(C)c3cc(C(C)c4cc(O)c(O)cc4O)c(O)cc3O)c(O)cc2O)c(O)cc1O</smiles>

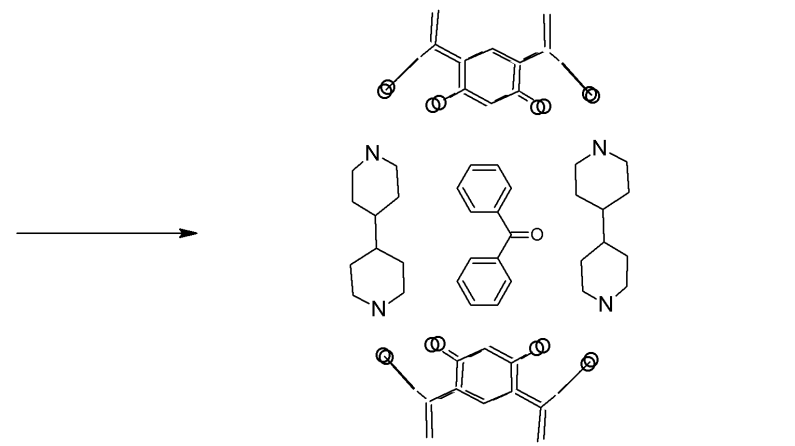

Figure 2. Chemical structures of CMCR, BRY, BZP and synthesis path of $\mathrm{CMCR} \cdot 2 \mathrm{BPY} \cdot \mathrm{BZP}$.

synthesis experiments were started by increase the temperature up to $120^{\circ} \mathrm{C}$. During the temperature increase, state of the powder samples were observed using an optical microscope. After the experiments, structures of the resulting powder samples were analyzed.

Heating device used is a melting point measuring instrument (Type ATM-01), AS ONE Co.). Structure of the product crystals were characterized by XRD (RINT-2000, Rigaku,: CuK $\alpha$ ), FT-IR (4200-type A, JASCO), TOFSIMS (ULVAC Inc.).

\section{Results and Discussion}

\subsection{Solventless Synthesis of CMCR"2BPY"BZP Just by a Slight Heating}

By heating (from room temperature to $120^{\circ} \mathrm{C}$ ) the physical mixtures of CMCR/BPY/BZP powders, some changes were recognized as shown in Figure 3. Initially, CMCR/BPY/BZP were homogeneously mixed in 1:2:1 molar ratio (Figure 3(a)). With an increase of the temperature, some part of the powders were changed as shown by red circle in Figure 3(b). Melting of BPY and BZP with lower melting point must occur partially. Further increase of the temperature, the melted areas were developed as shown in Figure 3(c) and new solid phase was appeared as shown by yellow circle in Figure 3(d).

In order to identify the structure of the resultant samples, powder XRD were measured (Figure 4). Though the experiment was started using physical mixtures of CMCR/BPY/BZP, the resulting XRD pattern (red line) is much different from these reactants (black patterns CMCR, BPY, BZP from the bottom). Rather the red line is good agreement with the theoretical pattern of CMCR-2BPY·BZP calculated using the single crystal structure data [3]. FT-IR measurements of the product showed shift of stretching vibration bands of hydroxyl groups from $3245 \mathrm{~cm}^{-1}$ (for pure CMCR) to $3316 \mathrm{~cm}^{-1}$, suggesting formation of hydrogen bonds between CMCR and BPY ligands. In addition TOF-SIMS measurements also showed the physical mixtures were changed to homogeneously mixed new compound. From these comparison results, it may be concluded that CMCR·2BPY·BZP must be synthesized just by heating the physical mixture of the three reactants.

\subsection{Experimental Evidence of Dissolution of CMCR into BPY/BZP Melt}

Here we want to point out another interesting point found in Figure 3. The reaction temperature in Figure 3 was 


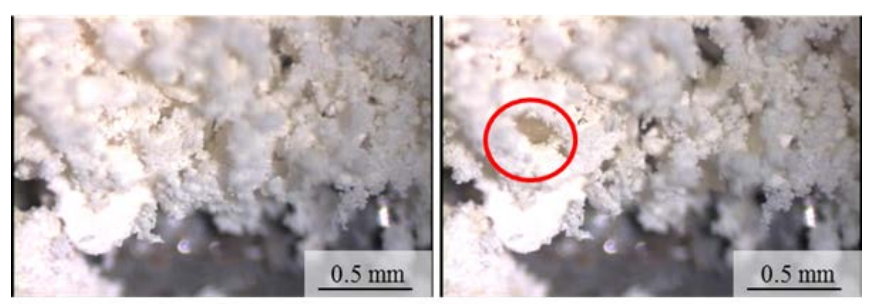

(a)

(b)

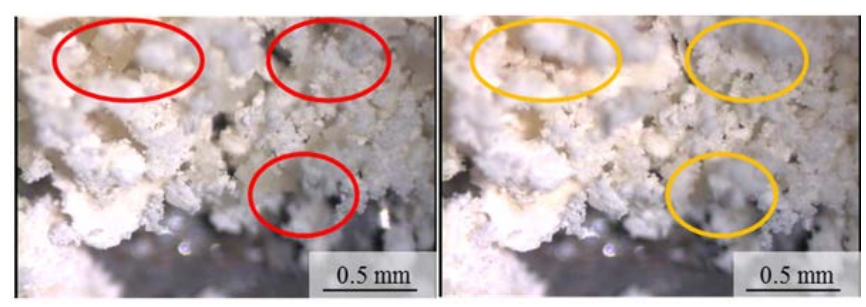

(c)

(d)

Figure 3. Changes in solid state caused by heating the physical mixture of CMCR/BPY/ BZP (1:2:1 in molar ratio). (a) $31^{\circ} \mathrm{C}$; (b) $50^{\circ} \mathrm{C}$; (c) $60^{\circ} \mathrm{C}$; (d) $115^{\circ} \mathrm{C}$.

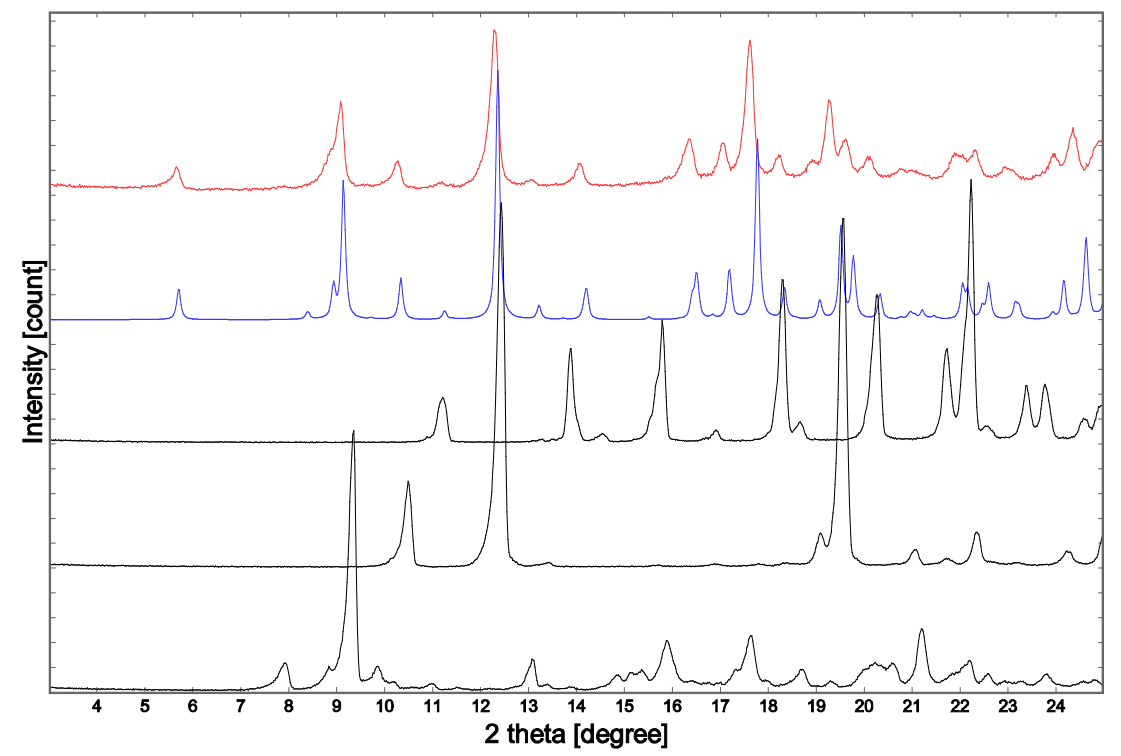

Figure 4. Powder X-ray diffraction patterns of reaction products (in red), theoretical pattern of CMCR·2BPY·BZP supramolecular crystal (in blue) and three reactants (black lines [CMCR, BPY, BZP from the bottom]).

up to $120^{\circ} \mathrm{C}$ which is much lower than melting point of CMCR $\left(>300^{\circ} \mathrm{C}\right)$. However, the reaction occurred. We are very interested in the reaction mechanism in such a "heterogeneous system". DidBPY/BPZ (melt) diffuse into the solid CMCR? To confirm this, additional experiment was performed. As shown in Figure 5(a), single crystal of CMCR (indicated by blue arrow) was prepared and powder mixture of BPY/BZP (shown by red arrow) was put onto it. With the elevation of temperature, BPY/BZP was started to melt at $40^{\circ} \mathrm{C}$ as indicated by yellow arrow in Figure 5(b) and morphology of the CMCR crystal was slightly changed (Figure 5(c) and Figure 5(d)). In Figure 5(e), outline of the CMCR crystal became unclear and crystalline state was changed drastically later (Figure 5(f) to Figure 5(i)). After the time shown by Figure 5(j), the melt disappeared while new solid phase appeared as shown by black arrow in Figure 5(I). From this experiment, disappearance of the CMCR is evident, suggesting the dissolution of CMCR into the BZP/BPY melt. For further confirmation of dissolution of the CMCR crystal into BPY/BZP melt, additional experiment was performed (Figure 6). In Figure 6, CMCR crys- 
(a)

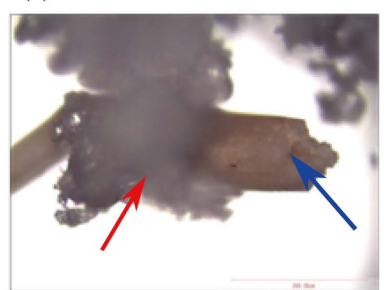

(e)

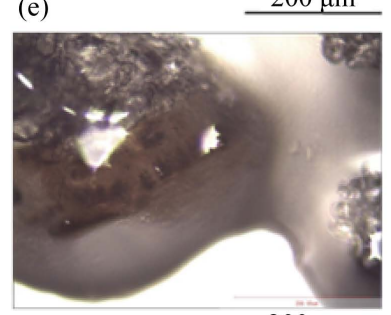

(i)

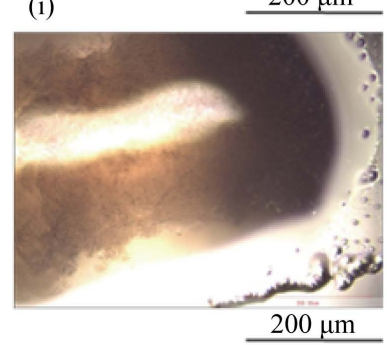

(b)

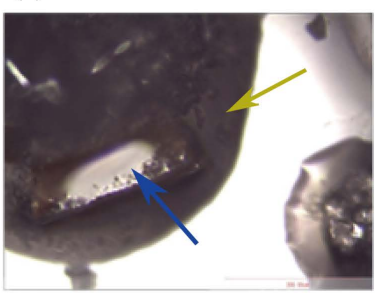

(f)

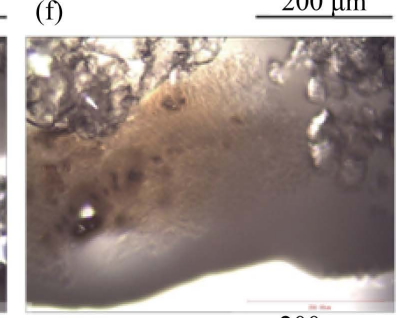

(j)

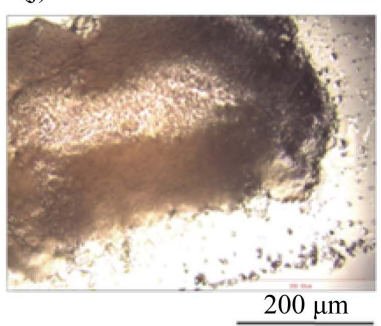

(c)

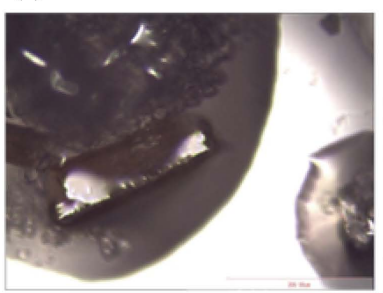

(g)
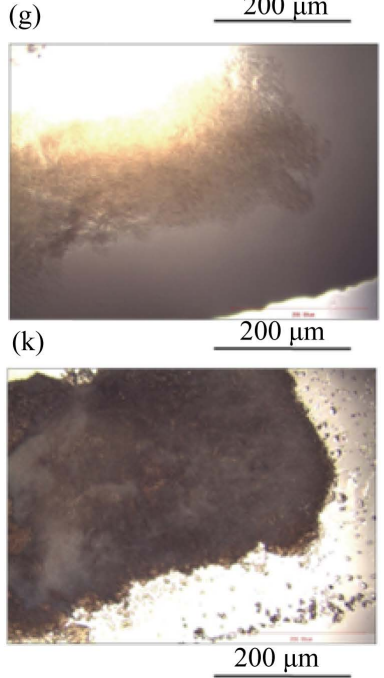

(d)

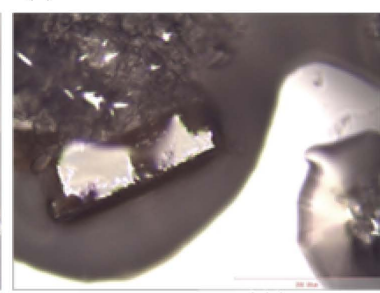

(h)

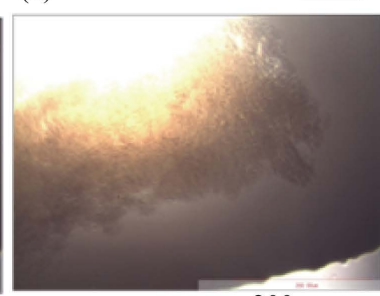

(1)

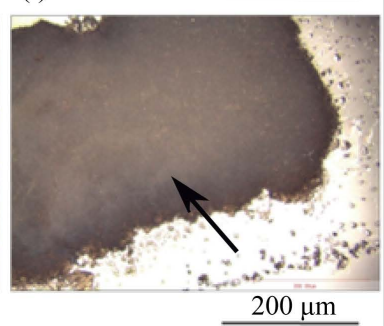

Figure 5. Changes in CMCR single crystal in the presence of BPY/BZP with the elevation of temperature. (a) BPY/BZP powder mixtures (red arrow) were put on CMCR single crystal (blue arrow) at $24^{\circ} \mathrm{C}$; (b) melting of BPY/BZP (yellow arrow), $40^{\circ} \mathrm{C}$; (c) $50^{\circ} \mathrm{C}$; (d) $60^{\circ} \mathrm{C}$; (e) $65^{\circ} \mathrm{C}$; (f) around this temperature state of the CMCR crystal was changed, $70^{\circ} \mathrm{C}$; (g) $90^{\circ} \mathrm{C}$; (h) $114^{\circ} \mathrm{C}$; (i) $123^{\circ} \mathrm{C}$; (j) the melt was disappeared and new crystalline phase was recognized, $125^{\circ} \mathrm{C}$; (k) $126^{\circ} \mathrm{C}$; (l) $127^{\circ} \mathrm{C}$.

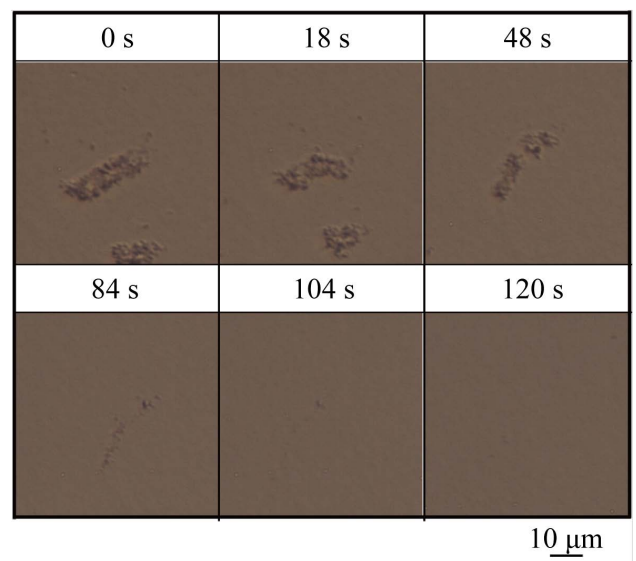

Figure 6. Photographic pictures showing dissolution of CMCR (center) into BPY/BZP melt (surroudings) observed at $101^{\circ} \mathrm{C}$ much lower than CMCR melting point $\left(>300^{\circ} \mathrm{C}\right)$.

tal was set directly into BPY/BZP melt. As can be seen in Figure 6, CMCR crystal dissolved into the melt. From these results, our proposed method, solventless synthesis just by giving a slight heat, may be applied for even for heterogeneous system in which one of reactants is high melting point compound.

Although many cases of organic supramolecular complex synthesized by mechanochemical method are reported [1], our method proposed in this study must be the most simple. Only a slight heat is essential point for occurrence of complex formation without solvent. For mechanochemical synthesis, heat generated by friction 
may cause the partial melting result in easiness of movement of molecules and occurrence of reaction. So the melting is essentially important for the reaction. In other words, even an enough heat is given, reaction may occur. Thus, the methodology proposed in this study is not limited to grinding and/or direct heating, even if enough energy may be added to the reaction molecules. Addition of such as microwave, ultrasound is next candidates for the heat sources.

\section{Conclusions}

1. CMCR·2BPY·BZP supramolecular complex was synthesized just by giving a slight heat to physical mixture of CMCR/BPY/BZP.

2. As the supramolecular formation mechanism, following explanation was concluded: Melting of BPY and BZP occurs at first and then CMCR was dissolved into the melt to form homogeneous state comfortable for the reaction to occur.

\section{References}

[1] James, A.L. and Friščić, T. (2013) Mechanochemistry. Chemical Society Reviews, 42, 7494-7496. http://dx.doi.org/10.1039/c3cs90058d

[2] Yokota, M., Doki, N. and Akagaki, H. (2015) Solventless Organic Reactive Crystallization at Mild Conditions. Advances in Chemical Engineering and Science, 5, 461-464. http://dx.doi.org/10.4236/aces.2015.54047

[3] Ma, B.-Q. and Coppens, P. (2004) Variable Conformation of Benzophenone in a Series of Resorcinarene-Based Supramolecular Frameworks. Crystal Growth \& Design, 4, 1377-1385. http://dx.doi.org/10.1021/cg0499562 